\title{
Public-Private Partnerships in the Context of the European System of Accounts (ESA95)*
}

\author{
Bernardino Benito, Francisco Bastida, María-Dolores Guillamón \\ Department of Accounting, Faculty of Economics and Business, University of Murcia \\ (Regional Campus of International Excellence “Campus Mare Nostrum”), \\ Murcia, Spain \\ Email: benitobl@um.es, alba@um.es,mdguillamon@um.es
}

Received April 13, 2012; revised May 20, 2012; accepted June 7, 2012

\begin{abstract}
This paper makes an analysis of the European System of Accounts (ESA95) financial treatment of Public-Private Partnerships (PPP). PPP are complex operations that allow incumbents to create infrastructures while hiding debt, with an eye on the next elections. However, the sad part of the story is that PPP are more expensive than traditional contracts in the long run. We think that PPP are not always the best solution. Governments should allocate the risk to the party that is the "least cost avoider", i.e., the party best suited to control and/or bear the risk. Without this approach, the public sector runs the risk of using PPP with the aim to achieve inadequate goals, for example to achieve a short-term improvement of public accounts, and at the same time, worsening the long-term financial picture.
\end{abstract}

Keywords: Public-Private Partnerships; ESA95; Government Debt; Government Deficit

\section{Introduction}

The public sector aims to provide the best services and the most complete infrastructures to the citizenry. Besides, these objectives must be achieved with the highest efficacy and transparency.

Regarding infrastructures, governments look for the best ways to get the required financial resources. The idea is to maximize the social and economic profitability of the public expenditure, but making it compatible with current legal limits on deficit and debt at the European level.

In the European Union (EU), the Article $104 \mathrm{C}$ of the Treaty on European Union (TEU), signed in Maastricht on 7 February 1992, and the PROTOCOL on excessive deficit procedure, establish the most important measures regarding budget discipline. To ensure the applicability of these measures and to enhance the third stage of Economic and Monetary Union, the June 1997 Council of Amsterdam set up the Stability and Growth Pact. This pact includes preventive and deterrent measures, and it initially was formed by two Council dispositions about reinforcement of budget situations' supervision, economic policies' coordination and concrete measures about excessive deficit procedure. Subsequently, in March 2005, the European Council made public the report "Im-

*This study has benefited from the financial support of the Spanish National R \& D Plan through the research project ECO2010-17463 (ECON-FEDER) and ECO2010-20522 (ECON-FEDER). proving the implementation of the Stability and Growth Pact”, which led to the adoption of two new regulations with new measures on budget surveillance of EU member countries.

The European System of Accounts (ESA95) is the key instrument in order to control the EU countries' budget policies (namely, deficit and debt). ESA95 is the basis of the European Statistical System.

This work focuses on two aspects. First, we analyse the most important public service management systems currently applied by governments. These new management systems usually finance infrastructures. Second, we assess the impact of these management systems on the measurement of the budget stability objective, according to ESA95 criteria.

The cooperation between public and private sector has always existed. However, in the last years, and especially after the European Growing Initiative adopted by the European Council in December 2003, there has been a great development of the newest cooperation strategies between public and private sector. These strategies mainly are Private Finance Initiatives (PFI) or more recently named also as Public-Private Partnerships (PPP). This development has been enhanced by the European Growing Initiative, which was established in close collaboration with the European Investment Bank. Thus, one of the main objectives of the Initiative was to boost the private collaboration in the expansion of the infra- 
structures deemed as essential for the EU economic growth.

To implement restrictive budget policies (budget balance or surplus), the collaboration between public and private sector is an interesting financing option. The idea is to put together two opposing objectives: increase of infrastructures and sound public finances. Accordingly, the EU has paid attention to these ways of government funding (PPP), to prevent their use to circumvent legal expenditure controls by removing public investment from the budget and debt from the balance sheet. The reason for the EU to control these practices it that the government assumes the majority of the risks and bears high fiscal costs [1-4].

With the aim of publishing a methodological regulation that ensures the coherence, the Eurostat issued a regulation on PPP: News Release No. 18/2004 of February 11th, Treatment of Public-Private Partnerships, which was later included and developed in Section 4 of the “ESA95 Manual on government deficit and debt”. This standard is the ESA95 technical standard currently used in the EU to account for PPP operations. Therefore, this standard is the cornerstone for the accomplishment of the budget stability objective in the EU. The next pages provide an insight into this standard.

The remaining of the paper is organized as follows. Section 2 presents the theoretical background. Section 3 describes the main PPP contracts' characteristics. Section 4 shows PPP accounting treatment according to ESA95. Section 5 summarizes and concludes.

\section{Theoretical Framework}

The Public Choice theory is one of the keystones of PPP. This theory states that taxpayers perceive debt-funded projects less costly than tax-financed ones, since they fail to perceive the actual cost of debt [5]. Taxpayers do not properly evaluate inter-temporal government budget restrictions. When government offers deficit-financed outlay program, taxpayers overestimate benefits of current expenditures and underestimate future tax burden. PPP contracts allow incumbents to invest in new infrastructures, which have a positive impact on voters' opinion about them, while deferring the payments of the infrastructure.

The theory of property rights explains the choice between budget and PPP when financing infrastructures. This theory shows that ownership matters when contracts are incomplete, thus preventing parties from stipulating all the potential eventualities in the contract [6]. Therefore, a key aspect in PPP is the appropriate risk sharing between private and public sectors established in the contract. If adequate risk is not shifted to the private sector, then projects become quasi public, but with the funding removed from the government's balance sheet. A critical issue in the risk transfer arrangements is to achieve pricing that correctly reflects the risks assumed by each party to the transaction [7].

Hart [8] developed a theoretical model of PPP within the framework of the property rights theory: con- ventional provision is good if the quality of the building can be well specified, whereas the quality of the service cannot be; in contrast, PPP is good if the quality of the service can be well specified in the initial contract, whereas the quality of the building cannot be.

The principal rationale for the adoption of PPP is that it addresses the deficit of physical infrastructures. Since Public investment is constrained by the limits on public spending imposed by membership of the single EU currency, PPP becomes an attractive way of funding investments. PPP involve contracting between government and the private sector under conditions of imperfect information. Theoretical developments such as principalagent theory provide an insight on PPP. This theory focuses on the design of "optimal contracts" in the face of asymmetries in the information and objectives of contracting parties. Emphasis is placed on the optimal allocation of risk as a means of "incentivising" agents to achieve principal's (government) objectives. PPP contracts specify which risks are borne by the government (principal) or contractor (agent). Moreover, as PPP contracts can connect different elements of infrastructure projects (for example, link the design and construction with one or all of the finance, operation and maintenance elements) there is better scope for transferring risk compared to traditional procurement methods. For example, payment may be withheld until assets are in operation thereby "encouraging" contractors to complete construction on time and within budget [4].

PPP can provide higher value for money compared with other approaches, if there is an effective implementation structure and if the objectives of all parties can be met within the contract. We must bear in mind that such contracts are complex to design, implement and manage. Sometimes they are not the best option: indeed in some cases it has been reported that they lead to an increase in the costs of services to citizens.

From a theoretical viewpoint, the main justification for PPP is the possibility to exploit the management expertise and the efficiency of the private sector without giving up quality standards of outputs, thanks to appropriate control mechanisms from the public party. This result is achieved by setting up complex contractual arrangements with the private sector operator ("agent”) where the public sector acts as the "principal”. In principal, agent relationships, the most complex issues are the precise definition of the tasks assigned to the agent, the measurement of the agent's performance, and the extent to which the principal can control the agent's performance for the 
whole duration of the contractual relationship. In PPP, the cornerstone is the allocation of risk between the two parties: well-designed PPP redistribute the risk to the party that is the "superior insurer" or the "least cost avoider", i.e., the party best suited to control and/or bear the risk [9].

\section{Public Works' Funding through Public-Private Partnership}

In order to fill the growing gap between necessary infrastructures and available resources, a key question arises: Which is the best way to make the investment in terms of value for money? In this context, since the nineties, PPP have spread in Europe. However, compared to PPP, traditional contracts still are more widely used, and they may be more appropriate in many projects. Even in the UK, where PPP is frequently used, traditional contracts finance $85 \%$ of public investment [10]. Thus, it is important to analyse the traditional model of public contracting as opposed to PPP. These are the main characteristics of the former:

- The public sector buys assets, not services, to the private sector.

- Assets are ex ante perfectly specified: the public sector designs the asset before the contracting process starts.

- The private sector is only responsible for the asset construction, since it is not responsible for the longrun asset yield after the guarantee period.

- The public sector is directly involved in the management of the project contract. If there are several companies singing the contract, the public sector usually takes the responsibility of coordinating them.

In spite of its common use, there is neither a generally accepted definition nor a unique model of PPP. It encompasses several relationship structures in which the private sector provides an asset or a service to the public sector. "Utilities" and transport projects based in administrative concessions have been widely used in the EU, especially in France, Italy and Spain. In this type of contracts, the company receives the payments made by service users, as it is the case, for example, in highway tolls. The UK broadened PFI to a wider scope of public infrastructures, and combined it with the introduction of services not paid by final users, but by the public sector.

PFI include several types of contract, such as:

- Short run management contracts with zero or small capital expenditure.

- Administrative concession contracts. These may involve the funding, design and construction of assets, with an important investment, together with the providing of related services.

- Joint ventures and partial privatizations, with a shared ownership between the public and the private sector
[10,11].

The main difference between PPP and a traditional contract is that in the former, private holder earnings are connected to service outcomes and to asset yield during the contractual period. The private holder is responsible not only for delivering the asset, but also for the project management and for the appropriate provision of the service during the contractual period. The timing of payments received by the company is completely different from traditional contracts.

The European Commission [12] highlights the following PPP characteristics:

- The relatively long duration of the relationship, involving cooperation between the public and the private partner on the project.

- The method of funding the project, partly from the private sector, sometimes by means of complex arrangements between the various players. However, public funds - in some cases rather substantial—-may complement the private funds.

- The key role of the economic operator, who is involved in different stages in the project (design, completion, implementation, funding). The public partner focuses primarily on defining the objectives to be attained in terms of public interest, quality of services and pricing, and it takes responsibility for ensuring compliance with these objectives.

- The distribution of risks between the public partner and the private partner, to whom the risks generally borne by the public sector are transferred. However, a PPP does not necessarily mean that the private partner assumes all the risks, or even the major share of the risks linked to the project. The precise distribution of risk is determined case by case.

Besides, the European Investment Bank [13] identifies these aspects in PPP:

- It is initiated by the public sector.

- It involves a clearly defined project and the sharing of risks with the private sector.

- It is based on a contractual relationship which is limited in time.

- It has a clear separation between the public sector and the borrower: there must be a private partner providing financial resources to fund the project [10].

PPP introduce new elements in the relationships between public and private sector. The financial reports must disclose the assets/rights and liabilities/commitments that arise in the provision of services and infrastructures under PPP. PPP, as opposed to traditional contracts or privatization, imply a risk sharing between public and private partners, so as to achieve a more efficient use of resources. Risk sharing and public resources involved determine the responsibility of the parties concerned in the project. 
There is an accounting debate around PPP, i.e., how it should be reported in the public sector financial statements. The concrete PPP at stake is the one in which the private holder is responsible for designing, building or reforming and financing an infrastructure. The contract enables the public partner to have the infrastructure at the citizens' disposal, whereas the private partner commits to provide the infrastructure and is entitled to be paid by the public partner.

When these new financing methods emerged, there was no clear accounting standard providing guidance on how to report them. Thus, many countries used them to develop infrastructures and public services while deferring payment and this way being able to control their deficits and debt. In this sense, Milesi-Ferretti [1] says that the imposition of numerical rules may encourage the use of dubious accounting practices, thereby reducing the degree of government budget transparency. These concerns have gained strength with the use of "creative public finance” by some European countries in order to meet the Maastricht budget deficit ceiling. In the same way, Koen and van den Noord [2] state that "creative accounting" operations may have merits of their own. PPP for instance have proliferated in several EU countries since the late 1990s, either at the national or sub-national level (e.g., in the form of PFI contracts in the UK and concessions in Spain). Instead of the government buying an asset and operating it, a private entity invests and owns the asset (at least partly and at least during the period of exploitation), selling the corresponding services to the government. PPP may be justified on the basis of efficiency, but from the perspective adopted here their main feature is that they initially reduce the government deficit and debt as compared with traditional financing of public infrastructures.

Regarding long-term PPP systems, we have observed that sometimes they are included among them concessions, operating and financial leases and foundation of government-owned companies. For this reason, in the next section we focus not only on PPP as such, but in these other formulas.

\section{Accounting Treatment according to ESA95}

\subsection{Concessions}

Within the framework of ESA95, “concession" refers to agreements where a public administration commissions a private company (normally after a public competition) to build, finance and manage an asset during the term of the contract.

The company charges directly to the final users (the citizens) for the use of the services the asset provides. The main part of the company's income comes from final users’ charges.

In the National Accounts, these assets are accounted as fixed capital formation in the company's balance sheet. This treatment does not impact on the deficit/surplus and debt of the public administration.

\subsection{Leases}

According to National Accounts, this practice takes place when a public administration uses a private company's asset during a period of time. Depending on who bears the majority of the risks and benefits of the ownership, the lease may be “operating" or "financial”. Both systems have a different impact on government accounting according to ESA95.

The operating lease payments affect the deficit/surplus and debt as long as they are made. In the financial lease, ESA95 establishes that the total value of the asset will be accounted as gross fixed capital formation in the moment the asset is at the government's disposal, affecting the deficit/surplus, and simultaneously the government debt increases. The repayment of capital by the government will reduce the debt, whereas the interest will affect the deficit/surplus.

In order to determine whether a concrete operation must be considered as operating or financial lease, ESA95 establishes eight questions (see Table 1). In a contract, not all the characteristics have to point to the same assessment of the contract, but some may lead to classify it as financial lease and some others may lead to consider it as an operating lease. In this situation, the relative importance of each characteristic of the project must be balanced.

\subsection{Foundation of Government-Owned Companies (GOC)}

When a new GOC is created, it is essential to determine its sectoral adscription, i.e., the company must be classified as public administration or non-financial company in the National Accounts. To do this, three steps are needed.

First, it should be assessed whether it is an "institutional unit" according to ESA95. If it is not the case, it is included in the accounts of the public administration that creates the company.

Second, whether the institutional unit is public or private has to be determined. The key here is who has the economic control of the company.

Third, it has to be determined if the public institutional entity is "market" or "non-market". When the main objective of the public institutional unit is the redistribution of national income and wealth, this unit has to be classified in the general government sector. However, when the main objective of the public institutional unit is financial intermediation, the unit is classified outside the 
Table 1. Factors influencing the distinction between operating and finance lease.

1. Who is responsible for the maintenance and insurance of the asset?

Assume government organizes and pays directly for the insurance and maintenance of the asset. This suggests a finance lease since government is bearing the risk of variations in such costs.

2. Who repays finance on early termination of a contract?

Assume the government is responsible for repayment of the corporation debt in the event of early termination of the contract. This suggests a finance lease since government is bearing that risk.

3. Who determines the nature of the asset?

Assume the corporation has significant and ongoing discretion on how to fulfil the contract; it makes the key decisions on design and construction of the asset; it decides how it is operated and maintained in order to provide the service required by the purchaser.

This suggests and operating lease.

4. Who bears the demand risk?

Demand for services provided by the asset might be greater or less than expected. Assume the corporation income is affected by the demand for the asset, such that government or other customers only pay for the amount of service consumed.

This suggests an operating lease.

5. Are there any third part revenues?

Assume the corporation uses the asset to provide services to customers other than just government, and the government is not exposed to the variability of third party demand, and these revenues are significant part of the total income from the asset.

This suggests an operating lease.

6. Does government pay less if the quality of service is not good enough?

Assume government payments are reduced when the service provided by the corporation is not up the required standard, even if this is because of problems with asset rather than how it is operated.

This suggests an operating lease.

7. Does government pay more if the corporation costs increase?

Assume government does pay more if there is an increase in the corporation costs related to the asset. For example the corporation might have to undertake more maintenance than expected.

This suggests a finance lease.

8. Who bears the residual value risk?

Assume government has the option, at the end of the contract, to buy the asset at the current market price, and that it is not bound to buy the asset at a pre-agreed price if it does not need it nor if the asset is not in good condition.

This suggests an operating lease.

general government sector, in the financial corporations sector. In other cases, it is necessary to decide if the unit is "market" or "non-market", i.e., whether more than $50 \%$ of production costs are covered by sales or not, respectively. This assessment will determine the sector in which the public institutional unit should be allocated.

In the above-mentioned circumstances, newfunding and management methods arise with the aim of establishing entities whose debt is not consolidated in public sector accounts.

Special attention must be paid to the constitution of securities funds. A securitisation operation occurs when a government transfers ownership rights over financial or non-financial assets, or the right to receive specific future revenues, to another unit, named the securitisation unit, who in exchange pays the originator. In order to finance the purchase, the securitisation unit borrows on its own account by, typically, issuing bonds called asset backed securities (ABS). The securitisation unit uses income generated by the transferred asset or by the specific future flows, or by sales of the transferred assets, to service its debt.

Usually the lenders will have a direct and legal claim on those assets or on those flows, in the event of the securitisation unit not paying the interest and principal due.

When the proceeds obtained from the sale of the assets are higher than the initial price paid to government, and the securitisation contract includes, in addition to the initial payment by the securitisation unit, a clause on additional future payments to government, a deferred purchase price (DPP) is said to exist and all or part of the proceeds are allocated to government.

Figure 1 shows the basic features of the operating mechanism of this funding method.

The key issue to be determined is whether a securitisation operation gives rise to revenue for the government, thereby reducing the public deficit if there is one, or whether the proceeds should be considered as government borrowing. Eurostat has decided the following (News Release No. 88/2007 of 25 June 2007) (this decision complements and amends the decision taken on the same issue in News Release 80/2002 of 3 July 2002): 


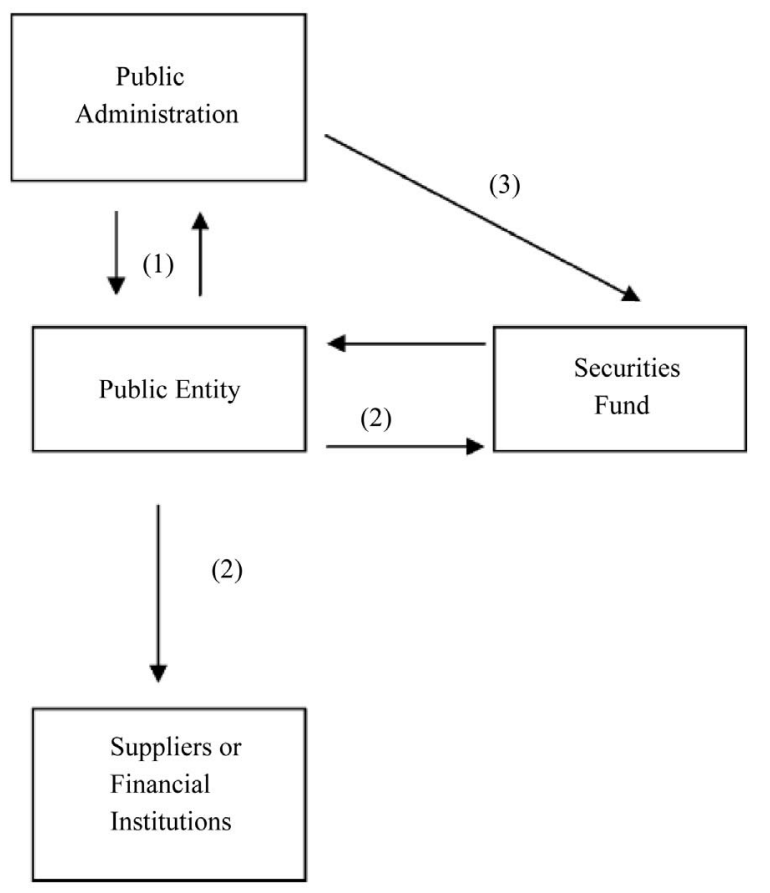

Figure 1. Operating mechanism of securities funds. (1) Public Administration asks the public entity for infrastructure building. This request gives rise to rights in favour of this public entity; (2) Public entity's rights are handed over to a securities fund, which pays to the entity the present value of these rights. With this money, the public entity can afford to pay builders or financial institutions for refunding previous borrowings; (3) Public Administration pays to the securities fund.

1. All securitisation of fiscal claims by government should be treated as government borrowing;

2. The existence of a DPP clause or of similar arrangements should lead to the classification of the securitisation operation as government borrowing;

3. A clause in the contract referring to the possibility of substitution of assets (except for marginal cases limited in scope and deriving purely from technical and material errors) should lead to the classification of the securitisation operation as government borrowing;

4. A clause of the securitisation contract stipulating ex ante government compensation to the unit (in case of government actions which are specifically related to the unit and not to different economic units more generally) should lead to the classification of the securitisation operation as government borrowing;

5. When government compensates (for instance in the form of cash, of debt assumption, or of direct or indirect guarantee) the unit ex post for specific events, although compensation was not originally foreseen in the contract, a reclassification of the operation as government borrowing must occur, with an impact on the surplus/deficit of government in the year in which the compensation is decided.

\subsection{Public-Private Partnerships (PPP)}

All these contracts were not specifically included in ESA95. However, their growing importance together with their peculiarities make us devote the next pages to analyse PPP. We will focus on the main characteristics that must be taken into account according to the methodological approach established by the EU statistical authorities.

The word "PPP" is not included either in the United Nations ${ }^{1} 1993$ "System of National Accounts (SNA)" or in the ESA95. The first time PPP appears in reference to the National Accounts is in the 18/2004 Eurostat Decision, 11 February 2004, with the aim of specifying its accounting treatment regarding the ESA95 "Excessive Deficit Procedure (EDP)". This 18/2004 Decision does not assess all the collaboration options between a private partner and a public administration, but it refers, exclusively, to the accounting recognition of several contracts. The basic criteria of the 18/2004 Decision were developed by a "task force" directed by Eurostat, in which several European countries participated. These criteria were published in the new chapter Part IV, Chapter 4.2 of the "ESA95 Manual on government deficit and debt", replacing all the former Chapter with the title "Long term contracts between government units and non-government partners".

Regarding the extent of the Eurostat methodological criteria, the "Consulting Group of National Accounts Experts for the UN National Account System" considers ESA95 Manual's regulation very relevant, since it has been established in accordance with the SNA principles. However, this consulting group has noted that, due to the complexity of these contracts, the criteria must be complemented with additional guidelines to ensure a coherent accounting treatment in all the circumstances.

Recently, one of the study groups that have evaluated the economic and financial relationships of PPP, the "Canberra Group II", has issued some recommendations for the next revision of the UN system, that will lead to a revision of the ESA. Thus, due to the growing importance of public administrations for the economy and financial policies, it is deemed essential that SNA incurporates a description and general principles for PPP accounting treatment.

Similarly, it is recommended to determine the economic ownership of the assets linked to a PPP contract through the evaluation of both how contract parties take the risks and benefits and who controls the asset.

Nevertheless, and until ESA is revised, PPP financial reporting in the National Accounts must meet the criteria established in section IV.4.2 of "ESA95 Manual on gov-

${ }^{1}$ This system establishes the World guidelines on National Accounts. The ESA is based on it. 
ernment deficit and debt". Specifically ${ }^{2}$, the Eurostat Decision:

“...will apply to long-term contracts in areas of activity where government normally has a strong involvement. These contracts often (but not always) correspond to what is referred to as 'Public-private partnerships', concluded with one or several partners, directly or through a special entity set up on purpose, and possessing expertise in the content of the contract over its lifetime. An important feature is that the contract mentions both the output of some specifically-designed assets, needing an initial capital expenditure, and the delivery of agreed services, requiring the use of these assets and according to given quality and volume standards.

This decision applies only in cases where government is the main purchaser of the services supplied by the partner, whether the demand originates directly from government itself or from third party users (as seen notably for health and education services, and the use of some transport infrastructures)."

Therefore, the criteria of the Eurostat Decision will be specifically applied to the contracts that meet certain characteristics:

- The realization of the object of the contract needs, at least in a first stage, an important capital expense, either for a new asset, or for a significant renovation, modernization or improvement of an existing asset, including the assets that are property of the Public Administrations and that are managed by them, but with the requirement that the expense of the renovation, etc., means an important part of the new value the asset achieves after its reformation.

- The contract must specifically mention the concrete assets that will be used to provide the agreed services, under the conditions fixed in the contract according to certain requirements of quality and quantity.

- The partner, or the group of partners, must have enough experience in the activity area the contract refers to.

- The key characteristic of these agreements is that the main buyer of the services is the public administration, that will acquire them by means of regular payments, being the demand originated by the own administration or by other users like third parties.

- Users' direct payments can exist, but these should represent a small, almost insignificant part, out of the partner's revenues. If this requirement is not met, the contract should be treated as another agreement type in the framework of the ESA (concession or other).

- The areas of activity of the contracts cover those public services in which, usually, public administrations have a very active participation, such as construction

${ }^{2}$ This Decision, in our opinion, should be more accurate, since there is some ambiguity. contracts and exploitation of highways, bridges, tunnels, hospitals, health centres, schools, universities, military equipment, cultural centres, prisons....

Once the essential characteristics of the contract are defined, the key issue is the preliminary classification of the assets involved in the PPP contract. This will make them appear either in the government or in the private partner balance sheet. In this situation, and with the specific aim of the National Accounts, Eurostat recommends that assets involved in PPP should be classified as nongovernment assets, and therefore recorded off-balance sheet for government, if both of the following conditions are met:

1. The private partner bears the construction risk.

2. The private partner bears at least one of either availability or demand risk.

In this case, and during the construction or renovation phase of the asset, the government accounts won't Register any operation. The government will only enter in the accounts the regular payments the public administration makes to the private partner, once the exploitation phase has started, which will affect public deficit or surplus when the purchases of services are recorded (as intermediate consumptions).

Therefore, the crucial element for the evaluation of an association project, as far as the classification of the assets is concerned, is the analysis of the risks borne by the contracting parties.

However, in this point, Eurostat remarks that this assessment does not consider risks not closely related to the asset and that can be fully separated from the main contract. This is the case when part of the contract might be periodically renegotiated, and subject to performance and penalty payments that do not significantly depend on the condition of the main assets.

In those cases in which the analysis of the risks doesn't allow to reach an evident conclusion, special attention must be paid to some of the additional elements of the contracts that can be used as appropriate supplementary criteria to make a decision, such as:

- The analysis of the nature of the partners (especially in the specific cases where the partners are government-owned companies).

- The importance of the public financing.

- The effect of the guarantees given by the public Administrations to the private partner, and

- The contractual clauses regarding the ownership of the assets involved at the end of the contract.

If the construction risk is borne by the government or if the private partner bears only the construction risk and no other risks, the assets are classified as government assets. This has important consequences for government finances, both for deficit/surplus and debt. The initial capital expenditure related to the assets will be recorded 
as government fixed capital formation, with a negative impact on government deficit/surplus. As a counterpart of this government expenditure, government debt will increase in the form of an "imputed loan" from the partner, which is part of the "Maastricht debt" concept. The regular payments made by government to the partner will have an impact on government deficit/surplus only for the part relating to purchases of services and "imputed interest".

The analysis of the risks borne by the contractual parties is the core element for the assessment of a PPP project, as far as the classification of the assets involved in the contract is concerned. As we said before, there are three main categories of generic risks that must be analyzed.

The first one is the "construction risk", that refers to the identification of which of the two contractual parts, public or private, should bear the economic consequences from: delays in the delivery, breaching of contract, cost increments over the initial budget, technical deficiencies and, finally, those coming from external effects that harm the realization of the contract. In relation to the analysis of this kind of risks, if the public Administration must make the contractual payments regardless the realization of the assets involved in the contract and their effective situation, this would be considered a proof that the Administration bears most of the risks associated to the asset construction. Otherwise, the construction risk would fall on the private partner.

Regarding the evaluation of the construction risk, the following key questions, among others, must be analyzed:

- Whether the contract establishes that the public administration must pay to the private partner before the construction ends and the provision of the services linked to the asset starts.

- The existence of sanctions in case of construction contract breaching: delivery terms, technical specifications, etc.

- Whether increments in the actual construction costs, as compared with the budget, don't lead to higher costs of the services provided by the private partner. The only exceptions would be force majeure or actions directly attributable to the government.

The second category is the "availability risk", when the partner cannot deliver the volume that was contractually agreed or cannot meet safety or public certification standards of services provided to final users, as specified in the contract. It also applies when the partner does not meet the required service quality standards, according to the contract, and resulting from an evident lack of "performance" of the partner. The government will be assumed not to bear such risk if it is entitled to reduce significantly (as a kind of penalty) its periodic payments, like any "normal customer" would require in a comercial contract. Government payments must depend on the effective degree of availability supplied by the partner for a given period of time. Application of the penalties where the partner is defaulting on its service obligations should be automatic, should also have a significant effect on the partner's revenue/profit and must not be purely "cosmetic" or symbolic.

In this case, the evaluation of the availability risk requires to check, among others:

- Whether the contract sets the parameters to value the quality of the services provided by the private partner (in an individualized way) and the level of readiness of the service.

- Whether the contract states the application of concrete deductions, for each one of the parameters used to measure the quality and availability of the services.

- Whether the contract establishes the regularity (monthly, quarterly, or other) to carry out the evaluations on the possible shortcomings in the quality and in the level of readiness of the service provided.

- Whether the contract clearly specifies that the amount of the resulting deductions is automatically applied to the payments the administration makes to the private partner.

- Whether the amount of deductions represents a really significant part of the partner's revenues.

A third category is “demand risk", covering variability of demand (higher/lower than stipulated in the contract) irrespective of the performance of the private partner. This risk should only cover a shift of demand not resulting from inadequate or low quality of the services provided by the partner or any action changing the quantity/ quality of services provided. To the contrary, it should result from other factors, such as business cycle, new market trends, direct competition or technological obsolescence. Government will be assumed to bear the risk where it is obliged to ensure a fixed level of payments to the partner regardless of the effective level of demand by the final user. This makes irrelevant the impact of fluctuations in demand level on the partner's profitability. However, this statement does not apply where the shift in demand results from an obvious government action, such as decisions of general government units (and thus not just the unit(s) directly involved in the contract) that represent a significant policy change, or the development of directly competing infrastructure built under government mandate.

Several points need to be addressed to evaluate the demand risk:

- Checking whether the system government payments fixation takes into account the effective level of demand;

- The effect of contractual clauses that ensure mini- 
mum payments to the private partner or that limit its additional benefits capacity;

- To check that the rates for bands of service use are calculated on the base of studies of quality of variability of the demand.

Finally, we must bear in mind that the concept of "private" entity must be interpreted as being outside the limits of the government. Therefore, it includes public, public-private or private companies providing services to the government on a market basis [14].

All mentioned above supports the idea of real transfer of demand and availability risks for the "not-consolidation" of this kind of operations in the "Public Administration" sector, discarding models of fixed and unconditional payments as those of some projects developed by the government.

Regarding the construction risk, two elements must be set before the draw up of the contract or before its bidding. On the one hand, the definition of investment costs before establishing the conditions of the provision of services. On the other hand, a thorough financial planning of flows the operation will generate.

\section{Concluding Remarks}

It is important to highlight that, according to PWC [10], PPP are, in general, more expensive than traditional debt operations. For example, as Hurst and Reeves [4] show, PPP implemented in Ireland have not resulted in significant innovations, failing to provide value for money. PPP are complex operations, difficult to analyse, and sometimes extremely sophisticated from a legal perspective. However, we must bear in mind that governments must keep on investing on social centres, road infrastructures, water-treatment plants, etc., and therefore the first point must be whether the investment is feasible from a traditional budgetary point of view. In case it is not viable, other alternatives will be considered (price subsidies, refundable advances, syndicated loans, subsidiary loans, exceptional financial aids, among others). These alternatives should have the appropriate budgetary surveillance, so as to accurately control the volume of operations the government is able to finance. In the same way that limits upon future expenses prevent current politicians from imposing excessive financial burdens to future politicians, PPP use should be justified from a budgetary and economic point of view.

The theoretical underpinnings of our assessment of PPP is twofold. On the one hand, according to the property rights theory, a key aspect in PPP is the appropriate risk sharing between private and public sector in the contract. If adequate risk is not shifted to the private sector, then projects become quasi public, but with the funding removed from the government's balance sheet. If this is the case, projects become more expensive in the long run, while politicians have been able to present a "good" financial situation in the short run. On the other hand, if we take into account the Public Choice theory, taxpayers overestimate benefits of current expenditures and underestimate future tax burden. Thus, PPP allow incumbents to create infrastructures, with an eye on winning the next elections. However, the sad part of the story is that these PPP are more expensive than traditional contracts in the long run.

As a final remark, we think that PPP are not always the best solution. Governments should allocate the risk to the party that is the "least cost avoider", i.e., the party best suited to control and/or bear the risk. Without this approach, the public sector runs the risk of using PPP with the aim to achieve inadequate goals, for example to achieve a short-term improvement of public accounts, and at the same time, worsening the long-term financial picture.

\section{REFERENCES}

[1] G. M. Milesi-Ferretti, "Good, Bad or Ugly? On the Effects of Fiscal Rules with Creative Accounting," Journal of Public Economics, Vol. 88, No. 1-2, 2004, pp. 377-394. doi:10.1016/S0047-2727(02)00076-2

[2] V. Koen and P. van den Noord, "Fiscal Gimmickry in Europe: One-Off Measures and Creative Accounting," OECD Economics Department Working Papers, No. 417, OECD Publishing, 2005.

[3] G. M. Milesi-Ferretti and K. Moriyama, "Fiscal Adjustment in EU Countries: A Balance Sheet Approach,” Journal of Banking and Finance, Vol. 30, No. 12, 2006, pp. 3281-3298. doi:10.1016/j.jbankfin.2006.05.010

[4] C. Hurst and E. Reeves, "An Economic Analysis of Ireland's First Public Private Partnership,” The International Journal of Public Sector Management, Vol. 17, No. 5, 2004, pp. 379-388.

[5] J. M. Buchanan, "Public Finance in Democratic Process, Fiscal Institutions and Individual Choice,” The University of North Carolina Press, Chapel Hill, 1967.

[6] O. Hart, "Firms, Contracts and Financial Structure," Clarendon Press, Oxford, 1996.

[7] C. Brown, "Financing transport infrastructure: for whom the road tolls," The Australian Economic Review, Vol. 38, No. 4, 2005, pp. 431-438. doi:10.1111/j.1467-8462.2005.00386.x

[8] O. Hart, "Incomplete Contracts and Public Ownership: Remarks, and an Application to Public Private Partnerships,” The Economic Journal, Vol. 113, No. 486, 2003, pp. C69-C76.

[9] European Parliament, "Public-Private Partnerships. Models and Trends in the European Union,” DG Internal Policies of the Union (IP/A/IMCO/SC/2005-161), 2006.

[10] PricewaterhouseCoopers, "Delivering the PPP Promise: A Review of PPP Issues and Activity,” PricewaterhouseCoopers, London, 2005. 
[11] M. Bult-Spiering and G. Dewulf, "Strategic Issues in Public Private Partnerships. An International Perspective,” Blackwell Publishing, Oxford, 2006.

[12] European Commission, "Green Paper on Public-Private Partnerships and Community Law on Public Contracts and Concessions,” COM(2004) 327 final.
[13] European Investment Bank, "Evaluation of PPP Projects Financed by the EIB,” Synthesis Report, 2005.

[14] R. Jones, "Public versus Private: the Empty Definitions of National Accounting," Financial Accountability \& Management, Vol. 16, No. 2, 2005, pp. 167-178. doi:10.1111/1468-0408.00103 